\title{
Avaliação técnico-econômica da colheita manual e mecanizada da cana-de-açúcar (saccharum spp) na região de Bandeirantes - Pr
}

\section{Technical and economical evaluation of hand and mechanized harvest of sugar cane (saccharum spp) in Bandeirantes - Pr}

\author{
Euripedes Bomfim Rodrigues ${ }^{1}$; Otavio Jorge Grigoli Abi Saab ${ }^{2 *}$
}

Resumo

A prática da queima antes da colheita da cana-de-açúcar vem sendo muito questionada, tanto pelo poder público quanto pela sociedade, preocupada com as questões ambientais. A colheita mecanizada da cana sem queima é apontada como um dos possíveis métodos para evitar a queima, e ainda não está sendo utilizada na região de Bandeirantes-PR. Neste trabalho avaliou-se a viabilidade técnica-econômica da utilização de colhedoras automotrizes de cana-de-açúcar sem queima em toletes, comparando com o custo da colheita manual da cana queimada, de modo a fornecer subsídios que auxiliem no planejamento de investimentos agrícolas. As determinações de campo foram realizadas em área pertencente à Usina de Açúcar e Álcool Bandeirantes. As variedades de cana-de-açúcar, Saccharum spp, utilizadas foram: RB 72-454, SP 81-3250 e RB 85-5113, plantadas em espaçamento de 1,40 m em nitossolos com declividade inferior a $12 \%$. Foram encontrados valores de 3,06 US $\$ . t^{-1}$ para o custo da colheita mecanizada da cana sem queima e de 4,14 US\$.t $t^{-1}$ para a colheita manual da cana queimada, observando-se uma redução de $32,74 \%$ em favor do custo da tonelada colhida mecanicamente. A capacidade operacional da máquina, estimada a 5,39 $\mathrm{km} \cdot \mathrm{h}^{-1} \mathrm{e}$ com eficiência de campo de $60 \%$, foi calculada em $0,45276 \mathrm{ha} \cdot \mathrm{h}^{-1}$.

Palavras-chave: Colhedoras, colheita mecânica, custo operacional

\begin{abstract}
The use of burning before the sugar cane harvest has suffered a lot of controversy for both the public organization and the society, worried about the environmental damages. The mechanized harvest of sugar cane has been discussed as one of the possible methods to avoid burning, and in the area around Bandeirantes this method has not been used yet. In this work it has been considered the technical economical viability of using self motive power reaper of sugar cane in rolls comparing to hand harvest cost of burning sugar cane so as provide subsidies that can help agriculture investments plans. The areas where the field decision has been performed were properties of Usina de Açucar e Alcool Bandeirantes, and the varieties of sugar cane used were: RB 72-454, SP 81-3250 and RB 85-5113, planted in a $1.40 \mathrm{~m}$ distance in a nitosoil arranged in down grade lower than $12 \%$. The cost of mechanical harvest of sugar cane was $3.06 \mathrm{US} \$ . \mathrm{t}^{-1}$ and the cost of burnt sugar cane hand harvest was $4.14 \mathrm{U} \$ . \mathrm{t}^{-1}$. This was a $32.74 \%$ reduction in the price per each ton harvested. The operational capacity of the machine, estimated at $5.39 \mathrm{~km} \cdot \mathrm{h}^{-1}$ and efficiency of $60 \%$ in the field, was calculated in $0.45276 \mathrm{ha}^{-1} \mathrm{~h}^{-1}$.
\end{abstract}

Key words: Green cane, mechanical harvest, operational cost

1 Professor Mecanização Agrícola FFALM - C.P. 70, CEP 86360-000, Bandeirantes-Pr, euri@ ffalm.br

2 Professor Mecanização Agrícola Departamento de Agronomia, Universidade Estadual de Londrina, Caixa Postal 6001, abisaab@uel.br

* Autor para correspondência 


\section{Introdução}

Na região de Bandeirantes, norte do Estado do Paraná, a cana-de-açúcar é a principal atividade agroindustrial e nenhuma forma de colheita mecânica vem sendo utilizada. O corte manual da cana-de-açúcar é o sistema utilizado, sendo efetuado após a queima.

A prática da queima antes da colheita vem sendo contestada por membros do Ministério Público através de ações judiciais, pela ação das comunidades preocupadas com os efeitos dessa prática agrícola sobre a saúde, a segurança, o meio ambiente e na qualidade de vida nos meios urbanos próximos às plantações. Pelos seus danos ambientais a queima da palha é questionada também pelos técnicos de governo da área ambiental, particularmente a poluição do ar e riscos de incêndios e desmatamentos.

No Paraná, segundo maior produtor nacional, a cana-de-açúcar é um dos principais produtos agrícolas, desenvolvendo-se principalmente na região norte e sua safra mais representativa foi colhida no período 2004/2005, correspondendo a 29.059.588 t, obtidas em 354.830 hectares cultivados (PARANÁ. 2006). O Paraná possui 27 unidades produtoras de açúcar e álcool, com impacto econômico sobre 126 municípios, onde são proporcionados 74 mil empregos diretos (ASSOCIAÇÃO DE PRODUTORES DE ALCOOL E AÇUCAR DO ESTADO DO PARANÁ, 2006). O município de Bandeirantes possui uma área plantada de 9.500 ha, produzindo 805.700 t de cana com rendimento médio de 85.000 kg.ha' ${ }^{-1}$ (PARANÁ, 2006).

A Associação dos produtores de Álcool e Açúcar do Paraná (ASSOCIAÇÃO DE PRODUTORES DE ALCOOL E AÇUCAR DO ESTADO DO PARANÁ, 2006) afirma que: o corte manual da cana continuará; apenas $8 \%$ da área de cana-de-açúcar deverá ter colheita mecanizada; e as usinas não adotam este sistema para não promover o desemprego. Porém, em virtude do aumento da área plantada, observa-se na região de Bandeirantes uma escassez de mão de obra, que pode acelerar o processo de mecanização da colheita. Costa Neto (2006) adverte que a mecanização da colheita de cana é inevitável e que uma colhedora de cana equivale a 100 cortadores, podendo chegar a um rendimento de 15 a 20 t.h $^{-1}$ contra 5 a 6 t.dia $^{-1}$ por pessoa. Afirma ainda que programas educacionais e de qualificação profissional são essenciais, assim como políticas públicas objetivas para minimizar reflexos do êxodo rural que provavelmente ocorrerá nos próximos anos.

O sistema de colheita é composto por três subsistemas: o subsistema de corte e carregamento, o subsistema de transporte e o subsistema de recepção. Cada subsistema tem interfaces que incluem aspectos comuns, os quais estabelecem um fluxo da matéria-prima do campo à indústria e que precisam ser alterados para compor-se ao novo arranjo técnico (RIPOLI; PARANHOS, 1987). A mudança na etapa do corte, de manual para mecânico, não é apenas uma mera substituição de uma técnica por outra. Em termos agrícolas significa combinar e otimizar alguns aspectos: o preparo do solo na lavoura, o dimensionamento dos equipamentos no campo, a equipe de manutenção e apoio, o treinamento do pessoal envolvido e as alterações no transporte e recepção da cana na indústria.

O desempenho econômico de uma máquina é definido por Ripoli e Mialhe (1982) como a associação entre os dados de custo-hora, formados pela estimativa de gastos de propriedade e de gastos operacionais (custeio), e os dados de desempenho operacional. Ripoli et al. (1999) avaliaram o desempenho de uma colhedora em cana sem queima em função da velocidade de avanço. No ensaio a colhedora operou em quatro diferentes velocidades: 1,$5 ; 3,0 ; 5,0$ e 7,0 km.h ${ }^{-1}$. Concluíram que a elevação da velocidade de deslocamento da colhedora provocou aumentos das capacidades efetiva bruta, operacional e efetiva líquida e a diminuição do consumo de combustível. Concluíram também que tanto a eficácia de manipulação e as perdas de matéria prima no campo não foram influenciadas. Observou-se que desde que não haja limitações como 
declividade, estado da superfície do terreno e treinamento do operador, que impeçam o deslocamento da máquina em velocidades mais elevadas, é possível esperar aumento da capacidade operacional com diminuição de custos, sugerindo uma capacidade de 110,18 t.h ${ }^{-1}$.

O custo operacional das maquinas agrícolas é resultado da soma dos valores dos custos fixos mais custos variáveis, sendo que os custos variáveis dependem da quantidade de uso que se faz da máquina e incluem combustíveis, óleo lubrificante, reparos, manutenção e mão de obra (BALASTREIRE, 1987). Ripoli et al. (2001) recomendam a abordagem do levantamento de custos pelo chamado "método do custo anualizado equivalente - CAE", desenvolvido a partir do conceito de anuidade equivalente para cálculo do custo anual de máquinas. Este método mostra que todos os valores são variáveis uma vez que se fazem projetos para toda a vida da máquina, desde sua aquisição até o momento de descarte ou de sucateamento. Os autores mostram também que os itens levados em consideração na construção do fluxo de caixa são: valor inicial e valor residual após o tempo de vida útil, juros, seguro, alojamento e administração, combustível, lubrificantes, filtros, comboios de manutenção e abastecimento, peças de reposição e serviços mecânicos e mão de obra do operador. Vieira (2003) observa que neste tipo de levantamento devese procurar talhões com características semelhantes e estar atento para separar por atividade os trabalhadores envolvidos.

Ripoli et al. (2001) trabalhando com o desempenho econômico de colhedora em cana sem queima, afirmam que a velocidade de colheita de $5,39 \mathrm{~km} \mathrm{~h}^{-1}$ apresentou o melhor desempenho econômico, obtendo resultados de 0,66 a 3,82 US\$.t $\mathrm{t}^{-1}$ de cana colhida. Já Kronka e Monteiro (1999) mostram um custo operacional médio em cana sem queima de 2,09 US\$.t ${ }^{1}$, trabalhando com o modelo Brastoft A-7.700 .

É fato que a adoção da colheita mecanizada será realidade em médio, ou até em curto prazo. Estudos complementares que visem uma análise técnicoeconômica prévia que permitam uma decisão a respeito de sua incorporação a este sistema produtivo, são de grande importância.

O objetivo do trabalho foi avaliar a viabilidade técnica econômica da utilização de colhedoras automotrizes de cana-de-açúcar sem queima em toletes, comparando com o custo da colheita manual da cana queimada, de modo a fornecer subsídios que auxiliem no planejamento de investimentos agrícolas.

\section{Material e Métodos}

As determinações de campo foram realizadas durante o período compreendido entre o dia 28 de junho a 08 de agosto de 2006, na propriedade denominada AAB-0025, com área de 77,871 ha, pertencentes à Usina de Açúcar e Álcool Bandeirantes, USIBAN, localizada no município de Bandeirantes, Estado do Paraná, com altitude aproximada de 400 $\mathrm{m}$ e a $17 \mathrm{~km}$ de distancia da indústria. O clima, pela classificação de Köeppen, é Cfa, ou seja, subtropical úmido, mesotérmico com verão quente, estiagem no inverno, média de $30 \mathrm{~mm}$ no mês mais seco e geadas menos frequientes. A precipitação média anual é de $1.300 \mathrm{~mm}$. (REIS, 2003).

As variedades de cana-de-açúcar, Saccharum spp, utilizadas foram: a RB 72-454 ( $4^{\circ}$ corte), a SP 81-3250 ( $4^{\circ}$ corte) e a RB $85-5113$ ( $3^{\circ}$ corte), plantadas em espaçamento de $1,40 \mathrm{~m}$ em solos de Terra Roxa Estruturada, atualmente Nitossolo (EMPRESA BRASILEIRA DE PESQUISA AGROPECUÁRIA, 1999), estruturada com declividade inferior a $12 \%$.

Utilizou-se a metodologia proposta por Vieira (2003) nas observações e coleta de dados. Procuraram-se talhões com características semelhantes de: declividade; variedade; e rendimento de cana cortada por talhão. Considerou-se no levantamento, o número de trabalhadores envolvidos, separando cortador, apontador, fiscal e técnico de produção, no caso da colheita manual. Foram anotados os tempos de trabalho em cada frente de 
corte, as quantidades envolvidas de mão de obra, máquinas, equipamentos e veículos de apoio.

No sistema de corte manual em cana com queima prévia, cada trabalhador corta 5 linhas de cana com espaçamento de $1,40 \mathrm{~m}$, que é amontoada em seguida em leiras para posterior medição e carregamento. Todo trabalho é acompanhado por um fiscal de turma.

A capacidade de campo operacional no corte manual feito pelos trabalhadores braçais é medida em toneladas cortadas por hora homem $\left(\mathrm{t} . \mathrm{h}^{-1}\right)$, e é relativa às operações do corte basal do colmo e o desponte apical dos ponteiros, considerando-se 5 linhas de plantio, espaçadas de 1,40 metros, para formação dos eitos, que são dispostos em montes. Segundo Vieira (2003) a quantidade de linhas cortadas por trabalhador, considerada ideal para o desempenho sem exigir esforço excessivo, é em torno de 7 metros.

Para o cálculo do custo da mão-de-obra no corte manual, é considerada mão de obra direta os cortadores e como indireta o fiscal, medidor, técnico de produção e aceiro. Para o sistema de corte mecanizado, considerou-se apenas a mão-de-obra do operador das colhedoras.

O carregamento no caso da colheita manual é feito por uma máquina carregadora, e utiliza-se uma ficha controle com adesivo constando o número do talhão a ser entregue na balança de recepção da cana na indústria. Com isso, tem-se o controle preciso do total em toneladas de cana colhida por área.

Com o número e a localização de cada talhão, o departamento de contabilidade da USIBAN forneceu a produtividade real registrada no fechamento do dia na balança, as planilhas de gastos com máquinas, folha de pagamento da mão de obra envolvida e demais valores necessários para cálculo dos custos.

Os componentes dos custos operacionais de tratores e colhedoras são amplamente conhecidos e incluem depreciação, juros sobre o capital, impostos, manutenção e reparos, combustível, lubrificantes e mão de obra do operador. Os custos fixos são aqueles que devem ser debitados independentemente da máquina ser ou não utilizada e incluem depreciação, juros, seguro e abrigo para a mesma. Os valores de custos utilizados foram os obtidos por Ripoli et al. (2001), na safra 98/99.

Para os cálculos do custo operacional da colhedora serão utilizados os preços médios de mercado, $\mathrm{R} \$ 825.0000,00$ para uma colhedora nova, apontados pela (CANA-DE-AÇÚCAR, 2006), potência de $246 \mathrm{kw}$ (MÁQUINAS, 2006) e R \$ 1,85 por litro de diesel que foi o valor pago pelo produto em Bandeirantes - PR na época da realização dos levantamentos e cálculos. Como referência, o valor do real brasileiro frente ao dólar americano adotado foi de $\mathrm{R} \$ 2,15$.

A velocidade de deslocamento empregada na simulação foi de $5,39 \mathrm{~km} \cdot \mathrm{h}^{-1}$, obtida por Ripoli et al.(2001), e que apresentou melhor desempenho econômico, considerando-se uma eficiência de campo de $60 \%$.

Os metros de linha (metros lineares), necessários porque muitos cálculos dependem desta unidade, foram obtidos dividindo-se a área respectiva pelo espaçamento entre linhas da cultura, no caso $1,40 \mathrm{~m}$.

\section{Resultados e Discussão}

\section{Colheita manual}

$\mathrm{Na}$ área considerada, somente na operação de corte manual da cana queimada, foram utilizadas 849,41 pessoas em média, o que justifica a preocupação de Costa Neto (2006) quanto ao desemprego e êxodo rural que poderá ser provocado pela colheita mecanizada.

Os resultados referentes à produção nas áreas avaliadas estão apresentados na Tabela 1. 
Tabela 1. Variedades de cana-de-açúcar, áreas ocupadas, número de cortes, produtividades, produção e respectivos totais utilizados para cálculos de custos.

\begin{tabular}{lccccc}
\hline Variedade & Área (ha) & $\begin{array}{c}\text { Metros de } \\
\text { linha }\end{array}$ & Cortes & $\begin{array}{c}\text { Produtividade } \\
\left(\text { t.ha }^{-1}\right)\end{array}$ & Produção (t) \\
\hline RB 85-5113 & 10,413 & $74.378,571$ & 4 & 74,616 & 776,98 \\
SP 81-3250 & 45,09 & $322.071,428$ & 3 & 114,451 & $5.160,62$ \\
RB 72-454 & 22,368 & $159.771,429$ & 4 & 87,998 & $1.968,34$ \\
\hline Total & $\mathbf{7 7 , 8 7 1}$ & $\mathbf{5 5 6 . 2 2 1 , 4 2 8}$ & & & $\mathbf{7 . 9 0 5 , 9 4}$ \\
\hline
\end{tabular}

Observa-se uma média de 101,526 t.ha-1 quando analisada a produção total desta área, acima da média nacional que está em 73,831t.ha-1 ${ }^{-1}$ segundo o (INSTITUTO, 2005) e acima também das médias de produção do Estado de São Paulo que é de 85 t.ha ${ }^{-1}$ (INSTITUTO, 2005) e do próprio Estado do
Paraná, 81,36 t.ha-1 (INSTITUTO, 2005). A variedade mais produtiva foi a SP 81-3250, que é também a de menor número de cortes.

As pormenorizações das operações envolvidas, manuais e mecanizadas, estão descritas na Tabela 2.

Tabela 2. Caracterização, classificação, quantificação (horas ou metros) e custo* das operações realizadas na colheita manual da cana-de-açúcar.

\begin{tabular}{ccccc}
\hline Operação & Classificação & Horas & Metros & Preço (R\$) \\
\hline Aceiros & Manual & 704 & - & 3,21 \\
Corte & Manual & - & $556.221,428$ & 0,05 \\
Esplanando & Manual & 2219 & - & 3,20 \\
Queima & Manual & 15 & - & 3,55 \\
& & & 7751 & 0,38 \\
Catação & Manual & - & - & 4,90 \\
Apoio de carregamento & Manual & 544 & - & 52,86 \\
Carregamento & Mecanizada & 185 & - & 88,78 \\
Conservação de estradas & Mecanizada & 16 & - & 57,28 \\
Reboque de veículos & Mecanizada & 79 & - & 57,28 \\
Reboque de carretas & Mecanizada & 112 & & \\
\hline
\end{tabular}

*Incluem: $13^{\circ}$ salário, D.S.R., Férias + 1/3, F.G.T.S. F.G.T.S.50\%, horas-extras, reflexo in itinere e in itinere.

Os custos calculados para cada unidade utilizada neste trabalho foram: $904,04 \mathrm{R} \$ \cdot \mathrm{ha}^{-1}, 0,1265 \mathrm{R} \$ . \mathrm{m}^{-1}$ e $8,90 \mathrm{R} \$ . \mathrm{t}^{-1}$. Os custos referentes a cada operação de corte manual da cana-de-açúcar com queima da palha, descrita na Tabela 2, estão apresentados na Tabela 3, assim como a totalização.
Em áreas distantes em até $20 \mathrm{~km}$ da indústria, o transporte da cana colhida não é cobrado, caso contrário elevaria o custo final a $\mathrm{R} \$ 94.116,33$, o que teria como resultado um custo por tonelada de $\mathrm{R} \$$ 11,90 , valor este praticamente idêntico ao custo médio apresentado pelo (CUSTO, 2006), para o Centro/ Sul, R\$11,92. 
Tabela 3. Custo de cada operação referente à colheita manual da cana-de-açúcar com queima da palha.

\begin{tabular}{lc}
\hline Operação & Custo $(\mathbf{R} \mathbf{\text { ) }}$ \\
\hline Aceiros & $2.259,84$ \\
Corte & $27.811,07$ \\
Esplanando & $7.100,80$ \\
Queima & 53,25 \\
Catação & $2.945,38$ \\
Apoio de carregamento & $2.665,60$ \\
Carregamento & $9.779,10$ \\
Conservação de estradas & $1.420,48$ \\
Reboque de veículos & $4.525,12$ \\
Reboque de carretas & $6.415,36$ \\
Fiscalização & 996,75 \\
Administração & $4.425,76$ \\
\hline TOTAL & $\mathbf{7 0 . 3 9 8 , 5 1}$ \\
\hline
\end{tabular}

\section{Colheita mecanizada}

Utilizando-se os valores de velocidade e eficiência de campo, obtidas no trabalho de Ripoli et al. (2001), $5,39 \mathrm{~km} \cdot \mathrm{h}^{-1}$ e $60 \%$ respectivamente, obteve-se como resultado de capacidade operacional para a situação analisada 0,45276 ha.h ${ }^{-1}$ ou 45,97 t.h ${ }^{-1}$. No trabalho original os autores encontraram valores de $61,25 \mathrm{t}^{-1} \mathrm{~h}^{-1}, \mathrm{o}$ que sugere uma produtividade de 135, 273 t.ha ${ }^{-1}$, na área representada, bastante superior à produção média de 101, 276 t.ha $^{-1}$ encontrada neste trabalho e também muito superior à média do Estado de São Paulo, de 85 t.ha $^{-1}$ (INSTITUTO, 2005).

Ripoli et al. (1999) encontraram para a colhedora automotriz os valores de 3.150 horas de trabalho em cada safra, derivado de 210 dias com 15 horas de trabalho, adotando 18.900 horas de trabalho em 6 anos de vida útil. Esses valores serviram de base neste trabalho para os cálculos dos componentes do custo horário, com base no método proposto por Balastreire (1987), e apresentados na Tabela 4.

Tabela 4. Componentes dos custos horários fixos e variáveis de uma colhedora automotriz de cana-de-açúcar, seus respectivos valores e totalização.

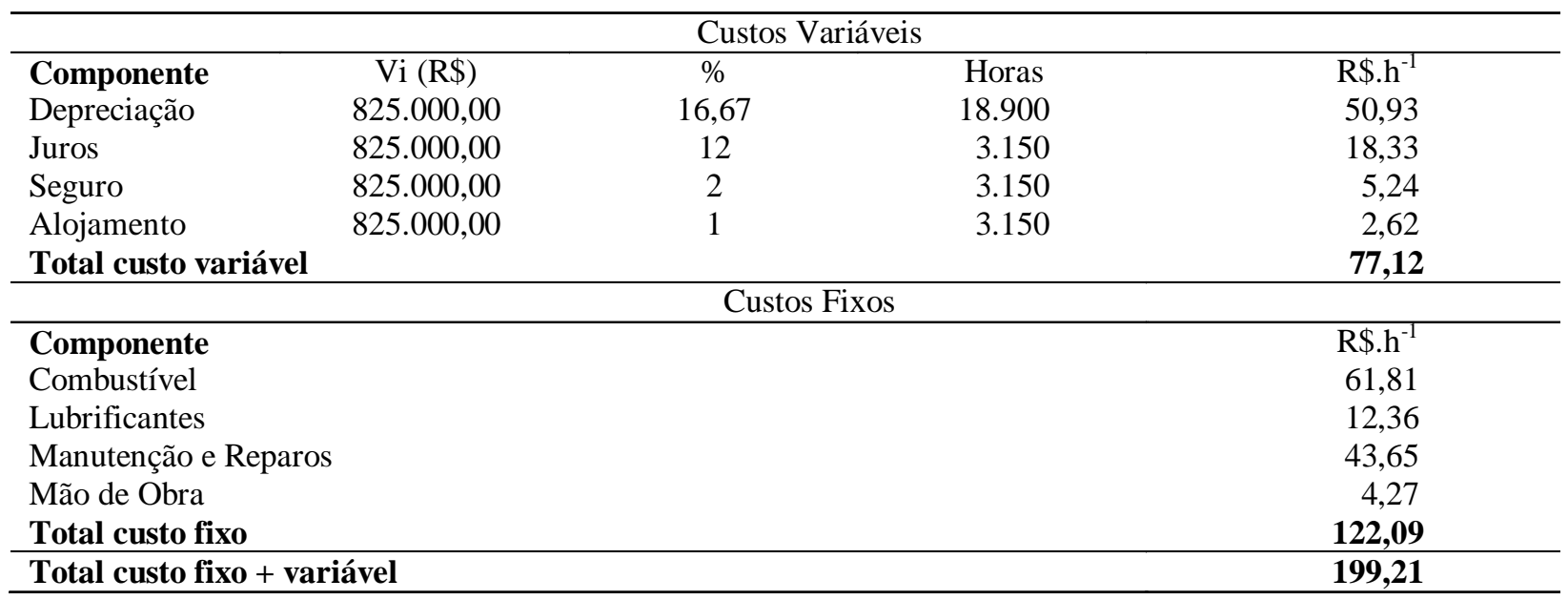


Os custos de conservação de estradas, reboque de veículos, reboque de carretas, fiscalização e administração, apresentados na Tabela 3 e considerados para a colheita manual, são comuns à operação de colheita mecanizada e foram, portanto, também considerados. Estes custos transformados em unidades de área e produção foram de 223,37 $\mathrm{R} \$ . \mathrm{ha}^{-1}$ e 2,25 R\$.t $\mathrm{t}^{-1}$, respectivamente. Estes valores acrescidos aos valores do custo hora apurados (Tabela 4), e transformados para custo por área e produção através da capacidade operacional encontrada por Ripoli et al. (2001), totalizaram 668,36 $\mathrm{R} \$ . \mathrm{ha}^{-1}$ e $6,58 \mathrm{R} \$ . \mathrm{t}^{-1}$, respectivamente.

A Tabela 5 apresenta a comparação dos custos do sistema de corte manual com queima da cana com o sistema de colheita mecanizada da cana sem queima.

Tabela 5. Custo unitário por área e produção para a colheita manual com queima e mecanizada sem queima da cana-de-açúcar.

\begin{tabular}{lcc}
\hline \multicolumn{1}{c}{ Tipo de colheita } & Custo área $\left(\mathbf{R} \$ \cdot \mathbf{h a}^{-1}\right)$ & ${\text { Custo produção }\left(\mathbf{R} \mathbf{.} \cdot \mathbf{t}^{-1}\right)}^{-1}$ \\
\hline Manual com queima & 904,04 & 8,90 \\
Mecanizada sem queima & 668,36 & 6,58 \\
\hline
\end{tabular}

Observa-se uma redução de $32,74 \%$ no custo da operação de colheita mecanizada de cana sem queima em relação à colheita manual de cana queimada. $\mathrm{O}$ valor de 3,060 US\$.t $\mathrm{t}^{-1}$, encontrado neste trabalho é compatível aos valores 2,09 US\$.t $\mathrm{t}^{-1}$, encontrado por Kronka e Monteiro (1999), e 3,82 US\$.t ${ }^{-1}$, por Ripoli et al. (1999).

Em relação à capacidade operacional a máquina é capaz de executar a tarefa de colheita na área estudada em aproximadamente 12 dias de 15 horas a um custo de $\mathrm{R} \$ 52.045,86$ com uma redução de $\mathrm{R} \$ 18.352,65$. Na colheita manual da cana queimada o tempo gasto foi de 07 dias, envolvendo 849,41 pessoas, com rendimento de 9,31 t.pessoa ${ }^{-1}$.

Velocidades e eficiências de campo baixas podem tornar o custo da colheita alto, diminuindo a competitividade da usina. Destaca-se o alerta de Ripoli e Paranhos (1987) para o fato de que o sistema de colheita é composto por três subsistemas: o subsistema de corte e carregamento, o subsistema de transporte e o subsistema de recepção, que precisam ser alterados para compor o novo arranjo técnico, assim como as condições de campo.

Destaca-se também que a parcela da população envolvida na colheita manual deve merecer por parte não só das autoridades, como também de toda sociedade, especial atenção quanto a novas formas de ocupação que visem melhorar o seu desenvolvimento, tanto econômico quanto social.

\section{Conclusão}

Para a área e as condições avaliadas a colheita mecanizada da cana-de-açúcar sem queima mostrouse técnica e economicamente promissora. Entretanto, devido aos altos custos envolvidos, é necessário expandir-se o estudo para a área total da USIBAN, visando à comprovação da viabilidade do investimento.

\section{Referências}

ASSOCIAÇÃO DE PRODUTORES DE ALCOOL E AÇÚCAR DO ESTADO DO PARANÁ. - ALCOPAR. Produtos: álcool, açúcar, cana-de-açúcar. Disponivel em: < http://www.alcopar.org.br/>. Acesso em: 28 abr. 2006.

BALASTREIRE, L. A. Máquinas agrícolas. São Paulo: Manole, 1987.

CANA-DE-AÇÚCAR: Mecanização avança. Revista Agrobrasil: balanço brasileiro do agronegócio 2006, Santa Cruz do Sul, 2006. Notícias do agronegócio. Disponível em : <http://www.revistaagrobrasil.com.br/site/ noticias_Integra.php?idNoticia=206027 >. Acesso em: 14 set. 2006. 
COSTA NETO, J. D. da. A cana em tempo bom. Revista CREA-PR, Curitiba, n. 41, p. 16-19, out. 2006.

CUSTO de produção de cana-de-açúcar. Ideaonline, Ribeirão Preto, 2006. Disponível em :<ideaonline.com.br/ ideamais/default.asp?act=01>. Acesso em 10 nov. 2006.

EMPRESA BRASILEIRA DE PESQUISA AGROPECUÁRIA - EMBRAPA. Centro Nacional de Pesquisa de Solos. Sistema brasileiro de classificação de solos. Rio de Janeiro, 1999.

INSTITUTO BRASILEIRO DE GEOGRAFIA E ESTATISTICA. Levantamento sistemático de produção agrícola, 2005. Disponível em : <http://www.ibge.gov.br/ estatistica/indicadores/agropecuarios/Ispa/default.shtm>. Acesso em : 8 abr. 2006.

KRONKA, P. F. B.; MONTEIRO, J. H. Desempenho operacional de colhedoras na Usina Iturama. In: SEMANA DE CANA DE PIRACICABA, 4., 1999, Piracicaba. Anais... Piracicaba: Saccharum, 1999. p.46-48.

MÁQUINAS agrícolas automotrizes produção, vendas internas e exportações. In: ASSOCIAÇÃO NACIONAL DOS FABRICANTES DE VEICULOS AUTOMOTORES. Anuário da industria automobilística brasileira 2007.São Paulo: ANFAVEA, 2006. Capitulo 3 Disponivel em : <htto://www.anfavea.com.br/anuario2007/ cap3_2007pdf>. Acesso em: 14 nov. 2006.

PARANÁ. Secretaria da Agricultura e do Abastecimento do Paraná - Seab. Produção agrícola. Disponível em:<http://www.pr.gov.br/seab>. Acesso em: 27 abr. 2006.
REIS, T. E. S. Determinação da compatibilidade de uso do solo e proposta de restabelecimento de áreas de reservas florestais em Bandeirantes-Pr através de análise de imagens e geoestatística. 2003. Tese (Doutorado em Agronomia) - Universidade Estadual de Londrina, Londrina, 2003..

RIPOLI, T. C. C.; MIALHE, L. G. Custos de colheita da cana-de-açúcar no estado de São Paulo, 1981/82. Álcool \& Açúcar, São Paulo, v. 2, n. 2, p. 18-26, 1982.

RIPOLI, T. C.; PARANHOS, S. B. Colheita.. In: PARANHOS, S. B.. Cana-de-açúcar, cultivo e utilização. Campinas: Fundação Cargill, 1987. p. 517-597.

RIPOLI, T. C.; NERY, M. S.; De LEÓN, M. J.; PIEDADE, S. M. S.. Desempenho operacional de uma colhedora em cana crua em função da velocidade de avanço. Engenharia Agrícola: Sociedade Brasileira de Engenharia AgrícolaSBEA, Jaboticabal, v. 19, n. 2, p. 199-207, 1999.

RIPOLI, T. C. C.; CARVALHO FILHO, S. M.; MOLINA JÚNIOR, W. F.; RIPOLI, M. L. C. Desempenho econômico de colhedora em cana crua. Engenharia Rural, Piracicaba, v. 12, p. 1-5, 2001.

VIEIRA, G. Avaliação do custo, produtividade e geração de emprego no corte de cana-de-açúcar, manual e mecanizada, com e sem queima prévia. 2003. 64 p..Dissertação (Mestrado em Agronomia) - Faculdade de Ciências Agronômicas, Universidade Estadual Paulista, Botucatu, 2003. 